\title{
DFT-Assisted Spectroscopic Studies on the Coordination of Small Ligands to Palladium: From Isolated Ions to Nanoparticles
}

\author{
Sebastiano Campisi, Cameron Beevers, Ali Nasrallah, C. Richard A. Catlow, Carine e. Chan-Thaw, \\ Maela Manzoli, Nikolaos Dimitratos, David J. Willock, Alberto Roldan,* and Alberto Villa*
}

Cite This: J. Phys. Chem. C 2020, 124, 4781-4790

Read Online

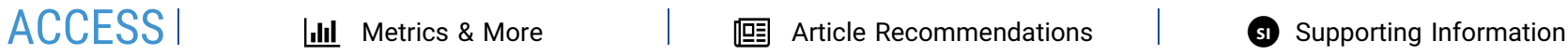

ABSTRACT: A combination of experimental spectroscopies (UV-vis and Fouriertransform infrared) and computational modeling was used to investigate the coordination of small ligands (aminopropanol and propanediol) to Pd species during the metal nanoparticle formation process. Differences emerged between $\mathrm{O}$ (propanediol) and $\mathrm{N}$-containing (aminopropanol) ligands. In particular, a strong interaction between the $\mathrm{NH}$ amino group and $\mathrm{Pd}^{2+}$ ions could be inferred on the basis of spectroscopic evidences, which was corroborated by theoretical simulations, which confirmed the preferential coordination of aminopropanol through the $\mathrm{NH}$ group. This interaction seems to potentially cause the aminopropanol ligand to control the particle shape through a selective blocking of $\mathrm{Pd}(100)$ facets, which promote the growth on the $\operatorname{Pd}(111)$ facets.

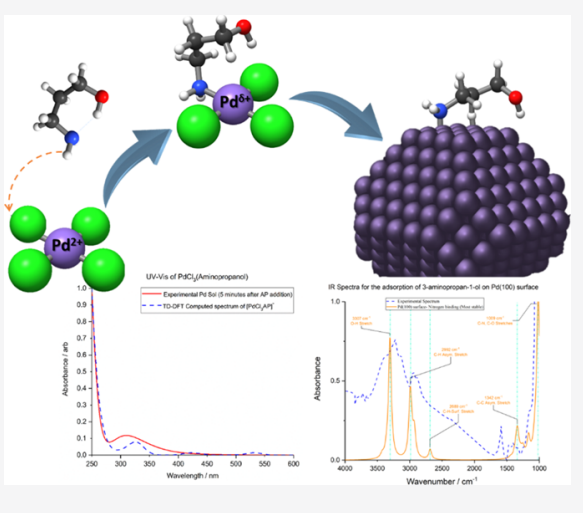

\section{INTRODUCTION}

In the last decades, metal nanoparticles (MNPs) have been used increasingly as key components for applications in several fields such as energy conversion and storage, biomedicine and life science, electronics, information technology, and catalysis, thanks to their unique and fascinating properties. ${ }^{1-4}$ Most of the physicochemical properties of MNPs (e.g., optical, catalytic, magnetic, and electronic properties) are highly dependent on a set of structural and morphological parameters, including composition, particle size, shape and exposure of facets, crystal structure, surface modification, and environment. Despite this strong relationship between their structure and function, the practical applications and the performances of MNPs are still limited by the lack of a clear predictability of the synthesis outcome in terms of size and morphological dispersion. ${ }^{5,6}$

Indeed, despite extensive studies and significant advances, the development of synthetic routes able to produce MNPs with an enhanced degree of compositional, dimensional, morphological, and structural control still remains an open challenge. This difficulty arises, in part, from the significant number of factors affecting solution-based methods which need to be considered and tuned in order to achieve the rational design of size- and shape-controlled MNPs syntheses. The metal reduction potential, the nature and concentration of precursors, the reducing agent, the solvent, the temperature, and the mass transfer phenomena have a considerable impact on the mechanisms of nucleation and growth..$^{7-10}$ In addition, capping agents are commonly used in solution-phase synthesis to stabilize MNPs and to prevent their aggregation. The capping agents are often selected from various types of molecules, such as thiols, amines, halides, carboxylic acids, phosphines, polymers, and surfactants. ${ }^{11-13}$ Capping agents can play multiple roles including providing colloidal stabilization and acting as structure-directing agents. ${ }^{7,11,14-19}$ Furthermore, as with conventional ligands, the capping agents can coordinate metal centers during different stages from metal precursors to MNPs. During the synthesis process, the metal precursor is decomposed and reduced into metal atoms, which then aggregate and evolve toward the formation of clusters and then nanoparticles (NPs). The role of the capping agents in the overall thermodynamics and kinetics of the nucleationgrowth processes derives from the different interactions with metal ions, MNPs, and several intermediates, as shown by many experimental studies. ${ }^{6,7,11,12,17,20,21}$ The concentration ratio of the capping agent and metal has been demonstrated to affect the final sizes of alkanethiolate-capped Au NPs. ${ }^{22}$ The interaction strength influences the particle size as reported by Karim et al. for Pd NPs synthesized in the presence of oleylamine (weak capping agent) or trioctylphosphine (TOP) (strong capping agent). ${ }^{23}$ The capping agent can also induce significant variations in the electrochemical reduction potential of metal ions, as suggested by the studies by Biacchi and

Received: October 18, 2019

Revised: December 28, 2019

Published: January 27, 2020 
Schaak concerning the effect of different polyols on the reduction of $\mathrm{Rh}$ salts. ${ }^{24}$

More recently, by combining in situ small-angle X-ray scattering (SAXS) and kinetic modeling, Mozaffari et al. investigated in detail the mechanisms of Pd NPs nucleation and growth. ${ }^{25}$ The study demonstrated that in different solvents (pyridine and toluene), the capping agents, acetate, and TOP, can exert a kinetic control on both the nucleation and growth rates, which was achieved by examining the concentration of the kinetically active metal precursor and the number of free surface sites on the respective NPs' facets.

The capping agent not only influences the formation of MNPs but can also irreversibly adsorb onto their surfaces, affecting their performance and utility, which can drastically reduce the activity of heterogeneous catalysts. ${ }^{26-28}$ It has been demonstrated that adsorbed capping agent molecules create an interphase, where diffusional, steric, and electronic effects can control and modify the overall activity and selectivity of catalytic reactions. $^{27}$ The reaction pathway is often governed by the preferential interactions between capping agent molecules and specific active sites (facets, edges, corners, and defects) on the MNP surfaces. ${ }^{28}$

For these reasons, a significant amount of research has been devoted recently to investigate the connection between metalcapping agent interactions and the formation mechanisms of MNPs in solution, as well as the nature and role of the local ligand environment of metal species in solution. Several studies have been reported using advanced characterization techniques (e.g., SAXS, liquid cell transmission electron microscopy, and extended X-ray absorption fine structure) to provide a molecular-level understanding of the roles of capping agents during the formation of MNPs. ${ }^{71,17,19-21,29-43}$ Here, we employ a combination of UV-visible (UV-vis) and Fourier transform infrared (FT-IR) spectroscopies and density functional theory (DFT) modeling to investigate the coordination of small ligands (diols and amino alcohols) to $\mathrm{Pd}^{2+}$ ions and $\mathrm{Pd}$ NPs. The complementary use of conventional spectroscopic techniques and theoretical modeling has already been demonstrated to be a powerful tool in investigating metalligand interactions in $\mathrm{Au}$ and $\mathrm{Ag} \mathrm{NPs} .{ }^{34-36,40,44}$ The $\mathrm{pH}$ dependence of interaction strength and conformation of thiolate and thione molecules at the surface of Au NPs has been studied by means of surface-enhanced Raman spectroscopy (SERS) combined with DFT modeling by Ansar et al. ${ }^{36}$ The synthesis of amidine-stabilized Ag NPs via hydrogenolysis of silver amidinate in the presence of hexadecylamine was explored by Cure et al. through nuclear magnetic resonance and SERS spectroscopies in combination with DFT simulations devoted to unraveling the coordination of ligands to Ag NPs. ${ }^{40}$ Singh et al. monitored the synthesis of curcumincapped Au NPs by in situ UV-vis Spectroscopy, and experimental results were correlated with DFT calculations exploring the formation of several complexes of curcumin with $\mathrm{Au}^{3+}$ ions in various conformational isomeric forms. ${ }^{35}$ In this study, we focused on Pd NPs, which were selected as a model metal system because of their prevalence and relevance to heterogenous catalysis. DFT-derived spectra were used to interpret the experimental results in detail. Our results illustrate the DFT-assisted spectroscopic approach to describe the ligand coordination to NP's facets. The species present in the experimental reaction solutions have been examined through comparison of experimental with computed spectra.

\section{EXPERIMENTAL SECTION}

2.1. Synthesis of Pd NPs. Solid $\mathrm{Na}_{2} \mathrm{PdCl}_{4}$ ( $0.094 \mathrm{mmol}$ of $\mathrm{Pd}$ ) and aminopropanol or propanediol water solution (1 wt $\%)(\mathrm{Pd} /$ capping agent $1: 100$ weight ratio) were added to 100 $\mathrm{mL}$ of $\mathrm{H}_{2} \mathrm{O}$. After $3 \mathrm{~min}, \mathrm{NaBH}_{4}\left(\mathrm{Pd} / \mathrm{NaBH}_{4}=1 / 8 \mathrm{~mol} / \mathrm{mol}\right)$ solution was added to the yellow-brown solution under vigorous magnetic stirring. A brown $\mathrm{Pd}(0)$ sol was immediately formed.

2.2. Spectroscopic Studies. UV-vis spectra of sols were recorded using a PerkinElmer $\lambda 25$ spectrophotometer in $\mathrm{H}_{2} \mathrm{O}$ between 190 and $1200 \mathrm{~nm}$ using a quartz cuvette. The samples were loaded into a rectangular quartz cuvette of $1 \mathrm{~cm}$ width and $3 \mathrm{~cm}$ height. The sample measurement was made with respect to a reference scan of the solvent (i.e., distilled water). Spectra were recorded after 10, 60, and 300 s from the addition of the capping agent.

FT-IR experiments were performed with cells allowing spectrum scanning on the liquid samples at room temperature. The FT-IR spectra were recorded using a PerkinElmer 2000 spectrometer (equipped with a cryogenic $\mathrm{HgCdTe}$ (MCT) detector). The spectra were acquired in the $4000-1000 \mathrm{~cm}^{-1}$ range with a $2 \mathrm{~cm}^{-1}$ resolution. To collect the FT-IR spectra of our aqueous solutions, we employed a commercial demountable transmission cell equipped with $\mathrm{CaF}_{2}$ windows (shown in Figure SI-1 of the Supporting Information). The solution is dropped onto a $\mathrm{CaF}_{2}$ window and sandwiched with another equal window such that no gas bubbles are trapped. This procedure implies that the amount of sample is very low, and the contribution of the solvent is negligible under these conditions.

The measured solution sample forms a thin liquid film between the two windows, which is typically less than $0.01 \mathrm{~mm}$ thick. It is not possible to measure the optical path, being that of the liquid film. Indeed, as the thickness is not constant from measurement to measurement, this type of cell is unsuitable for quantitative analysis.

2.3. Computational Details. This project uses DFT as incorporated within the ORCA ${ }^{45}$ and VASP (Vienna Ab initio Software Package $)^{46-49}$ simulation codes to model precursor molecules and experimentally formed NPs, respectively, the latter of which is modeled as extended periodic surfaces. The Perdew-Burke-Ernzerhof (PBE) exchange-correlation functional $^{50,51}$ was employed to account for the exchange and correlation effects on valence electrons with the projector augmented-wave method used to represent atomic core states. $^{52,53}$ To ensure consistency between periodic and nonperiodic simulations, extended tests were carried out using PBE and Becke-Perdew-86 functional (BP86). These consistency tests have shown the PBE functional to be a reasonable compromise between cost and accuracy for the second-row transition metals modeled using both periodic and atom-centered DFT methodologies. ${ }^{54}$ Dispersion effects were included in both atom-centered and plane-wave models using Grimme's empirical DFT-D3 model. ${ }^{55}$ For nonperiodic, atomcentered models, DFT-D3BJ (DFT-D3 with Becke-Johnson damping) was used to prevent artificial short-range repulsive interactions. ${ }^{55-58}$

Dipole correction along the $Z$-direction of the periodic slab model was applied when necessary. A Monkhorst-Pack grid was used to sample the Brillouin zone. ${ }^{59}$ For optimization calculations, the number of $k$-points used was $7 \times 7 \times 7$ for the optimization of the fcc unit cell bulk structure, and $7 \times 7 \times 1$ 
for the surfaces. For the adsorption calculations on the (111) surface, a 5 atomic layer-thick slab with a $p(4 \times 4)$ surface supercell ( 80 atoms) was employed. For the (100) surface, a $c(3 \times 3)$ surface slab was constructed, again 5 layers thick $(90$ atoms). During optimization calculations, the top two layers of the slabs were relaxed and the lower 3 layers fixed at their optimized bulk positions. A $3 \times 3 \times 1 k$-points sampling was used for all surface calculations. The periodically repeated slabs were separated by a $20 \AA$ vacuum layer along the $Z$ direction, which is enough to avoid any spurious interaction with periodically replicated images. A kinetic energy of the plane waves was set to $400 \mathrm{eV}$ ensuring no Pulay stress. The convergence criterion was set such that the calculations converge when the forces are less than $0.02 \mathrm{eV} \AA^{-1}$ for adsorption calculations, $0.001 \mathrm{eV} \AA^{-1}$ for the bulk, and $0.01 \mathrm{eV}$ $\AA^{-1}$ for surface optimization calculations. The adsorption energy was computed using eq 1 .

$$
E_{\mathrm{ads}}=\left(E_{\mathrm{ad}+\mathrm{sl}}-E_{\mathrm{sl}}-E_{\mathrm{ad}}\right)
$$

where $E_{\mathrm{ad}+\mathrm{sl}}$ is the energy of the adsorbate adsorbed on the slab, $E_{\mathrm{sl}}$ is the energy of the naked slab, and $E_{\mathrm{ad}}$ is the energy of the adsorbate in the gas phase, that is, in a cell large enough to avoid intermolecular interactions.

The ORCA implementation of Karlsruhe quadruple zeta with valence and polarization function basis set (def2-QZVP), the auxiliary Weigend basis set $(\operatorname{def} 2 / \mathrm{J})$, and StuttgartDresden effective core potentials was used for all nonperiodic atom-centered DFT calculations. ${ }^{60-62}$ The convergence criteria for these calculations were an energy change of 2.72 $\times 10^{-5} \mathrm{eV}$ with a maximum gradient of $5.14 \times 10^{-3} \mathrm{eV} \AA^{-1}$ and a maximum displacement of $5.29 \times 10^{-4} \AA$. Analytical frequency calculations were also performed to optimize and confirm the geometry of the aminopropanol ligand molecular precursor.

The species present in the reaction solutions have been examined through comparison of experimental with computed spectra. Simulated UV-vis spectra were calculated using the simplified Tamm-Dancoff approximation of time-dependent DFT (sTDA-DFT), which has been shown to give good agreement with TD-DFT for the electronic transition energies, although it is known that intensities calculated using this method are less reliable. ${ }^{63}$ The calculation efficiency of sTDADFT has also been increased by employment of the RIJCOSX approximation of the Coulomb and exchange integrals. Structures showing sTDA-DFT transitions consistent with the wavelength of experimentally observed bands were also calculated using the more demanding TD-DFT with the RIJCOSX integral approximation. TD-DFT spectra were examined using the Multiwfn software package, which applies Gaussian curve broadening. ${ }^{64}$ Calculated excitations and orbital compositions were determined using the Mulliken method. ${ }^{65}$ Localized orbital centroid analysis was also undertaken in order to examine the ligand bonding and oxidation state of the $\mathrm{Pd}^{2+}$ ions in the NP precursor molecule using the methodology of Vidossich and Lledós. ${ }^{66}$ This utilized the ORCA software package's implementation of the PipekMezey population-localisation methodology to derive localized orbitals from the DFT-calculated electronic structure. ${ }^{67,68}$ The gas-phase energy changes of reaction, $\Delta E_{\mathrm{r}}$, were calculated using eq 2.

$$
\Delta E_{\mathrm{r}}=\sum E_{\text {products }}-\sum E_{\text {reactants }}
$$

\section{RESULTS AND DISCUSSION}

The coordination of the capping agent to $\mathrm{Pd}^{2+}$ ions and $\mathrm{Pd}$ NPs was investigated by UV-vis and FT-IR spectroscopies. 3-

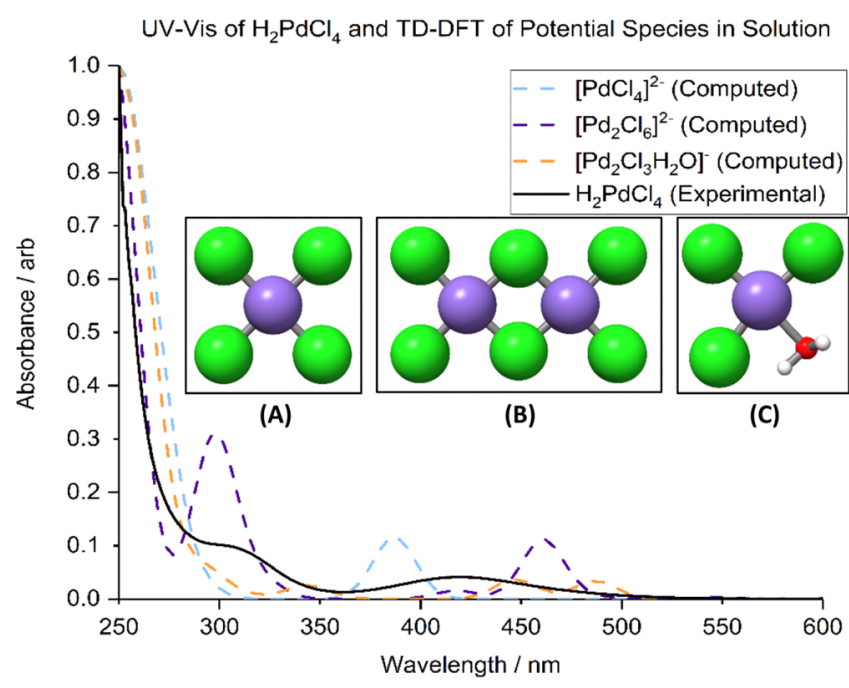

Figure 1. Experimental UV-vis spectra of $\mathrm{H}_{2} \mathrm{PdCl}_{4}$ in solution at $\mathrm{pH}$ 3 (black), computed UV-vis spectra of $\left[\mathrm{PdCl}_{4}\right]^{2-},\left[\mathrm{Pd}_{2} \mathrm{Cl}_{6}\right]^{2-}$, and $\left[\mathrm{PdCl}_{3} \mathrm{H}_{2} \mathrm{O}\right]^{-}$. Inset: Structures of $\mathrm{PdCl}_{4}{ }^{2-},(\mathrm{A}) ; \mathrm{Pd}_{2} \mathrm{Cl}_{6}{ }^{2-},(\mathrm{B})$; and [ $\left.\mathrm{PdCl}_{3}\left(\mathrm{H}_{2} \mathrm{O}\right)\right]^{-},(\mathrm{C})$. Color code: $\mathrm{Pd}$ : cyan; $\mathrm{Cl}$ : green; O: red; and $\mathrm{H}$ : light gray.

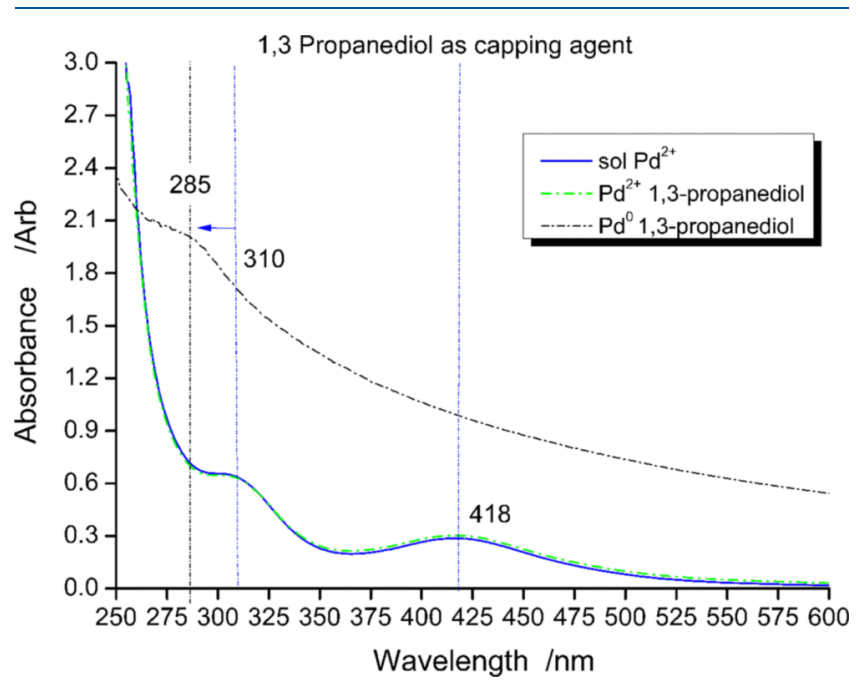

Figure 2. UV-vis spectra of $\mathrm{H}_{2} \mathrm{PdCl}_{4}$ in solution (blue) in the presence of the capping agent $\mathrm{PD}$ (green), Pd with $\mathrm{PD}$ reduced (black).

Aminopropanol (AP) and 1,3-propanediol (PD) were studied as model capping agents for the Pd sol. These molecules were selected because their molecular structures resemble the repeating units of several polymers commonly used as capping agents for Pd NPs (e.g., poly vinyl alcohol, poly ethylene glycol, and poly vinyl pyrrolidone).

The coordination of the capping agent molecules to $\mathrm{Pd}^{2+}$ ions was monitored in real time by UV-vis spectroscopy under typical synthetic environments for the generation of the Pd sol. The starting $\mathrm{H}_{2} \mathrm{PdCl}_{4}$ salt in solution (the black line in Figures $1-3$, which show the observed and calculated spectra) is characterized by UV-vis bands at 310 and $418 \mathrm{~nm}$. These bands could be associated to ligand to metal charge-transfer 


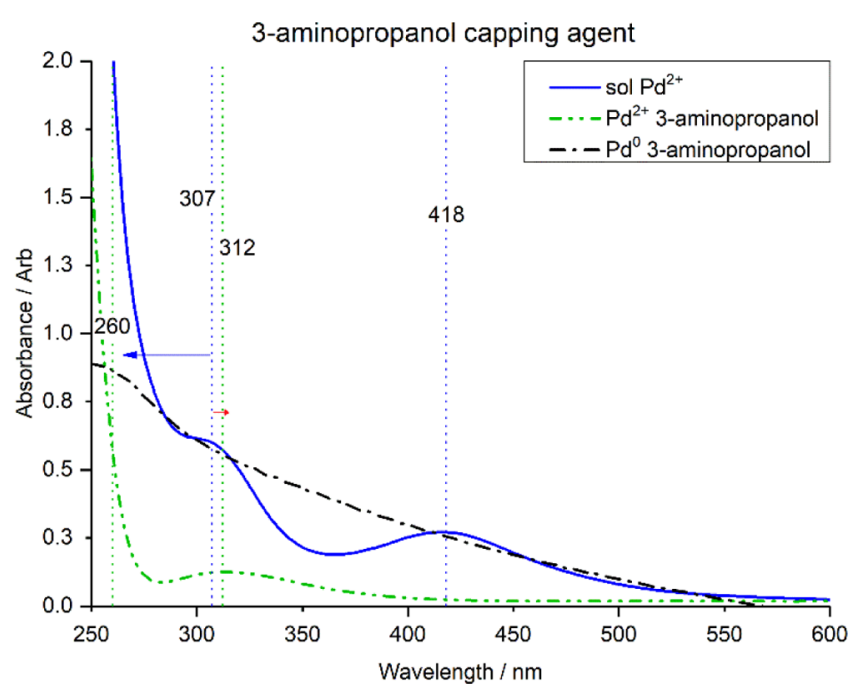

Figure 3. UV-vis spectra of $\mathrm{H}_{2} \mathrm{PdCl}_{4}$ in solution (blue), in the presence of the capping agent AP (green), Pd with AP reduced (black).

Table 1. Energy Change of Reaction $\left(\Delta E_{\mathrm{r}}\right)$ for the Formation of $\mathrm{Pd}_{2} \mathrm{Cl}_{6}{ }^{2-}$ and $\left[\mathrm{PdCl}_{3} \mathrm{H}_{2} \mathrm{O}\right]^{-}$from $\mathrm{PdCl}_{4}$

\begin{tabular}{cc} 
products & $\Delta E_{\mathrm{r}} / \mathrm{kJ} \mathrm{mol}^{-1}$ \\
$\mathrm{Pd}_{2} \mathrm{Cl}_{6}^{2-}$ & -252 \\
{$\left[\mathrm{PdCl}_{3}\left(\mathrm{H}_{2} \mathrm{O}\right)\right]^{-}$} & -215 \\
\hline
\end{tabular}

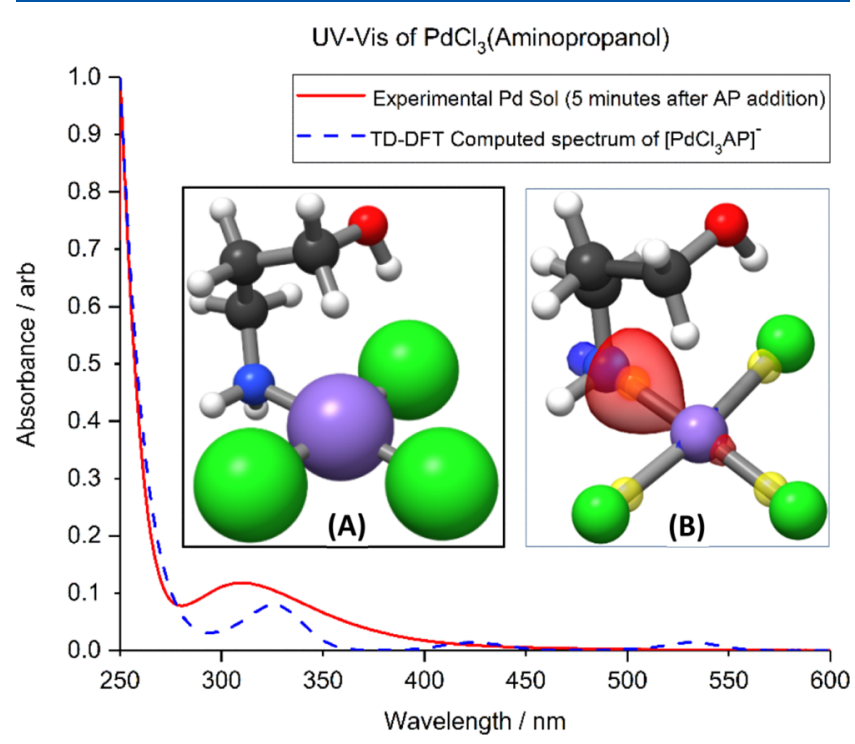

Figure 4. UV-vis spectra of $\mathrm{PdCl}_{4}{ }^{2-}$ sol in the presence of the capping agent AP (green) and computed TD-DFT spectrum of $\mathrm{PdCl}_{3} \mathrm{AP}$ (blue dashed). Inset: (A), $\mathrm{PdCl}_{3} \mathrm{AP}^{-}$lowest energy geometry; (B), $\left[\mathrm{PdCl}_{3} \mathrm{AP}\right]^{-}$with the $\mathrm{Pd}-\mathrm{N}$ localized bonding orbital and the centroids for the $\mathrm{Pd}-\mathrm{N}$ and $\mathrm{Pd}-\mathrm{Cl}$ bonds. Color code: $\mathrm{Pd}$ : lilac; $\mathrm{Cl}$ : green; $\mathrm{O}$ : red; $\mathrm{N}$ : blue; $\mathrm{C}$ : dark gray; $\mathrm{H}$ : white; and localized orbital centroids: translucent yellow.

(CT) and $\mathrm{d}-\mathrm{d}$ electronic transitions. Typically, bands originated from $\mathrm{d}-\mathrm{d}$ transitions are much less intense and more resolved than $\mathrm{CT}$ transitions. On the other hand, the identification of the $\mathrm{Pd}$ species responsible for these spectral features is no trivial matter. As reported by Elding, the predominant species found in acidic media are $\mathrm{PdCl}_{4}{ }^{2-}$ and $\left[\mathrm{PdCl}_{3}\left(\mathrm{H}_{2} \mathrm{O}\right)\right]^{-69}$ Spectroscopic evidences of the formation of
Table 2. Energy Change of Reaction for the Potential Products of the Reaction between $\mathrm{PdCl}_{4}$ and $\mathrm{AP}$

\begin{tabular}{lc} 
potential products & $\Delta E_{\mathrm{r}} / \mathrm{kJ} \mathrm{mol}^{-1}$ \\
$\mathrm{PdCl}_{2} \mathrm{OHAP}$ (cis) & -207 \\
$\mathrm{PdCl}_{2} \mathrm{OHAP}$ (trans) & -188 \\
$\mathrm{PdCl}_{3} \mathrm{AP}$ & -305 \\
$\mathrm{PdCl}_{2} \mathrm{AP}_{2}$ & -295 \\
\hline
\end{tabular}
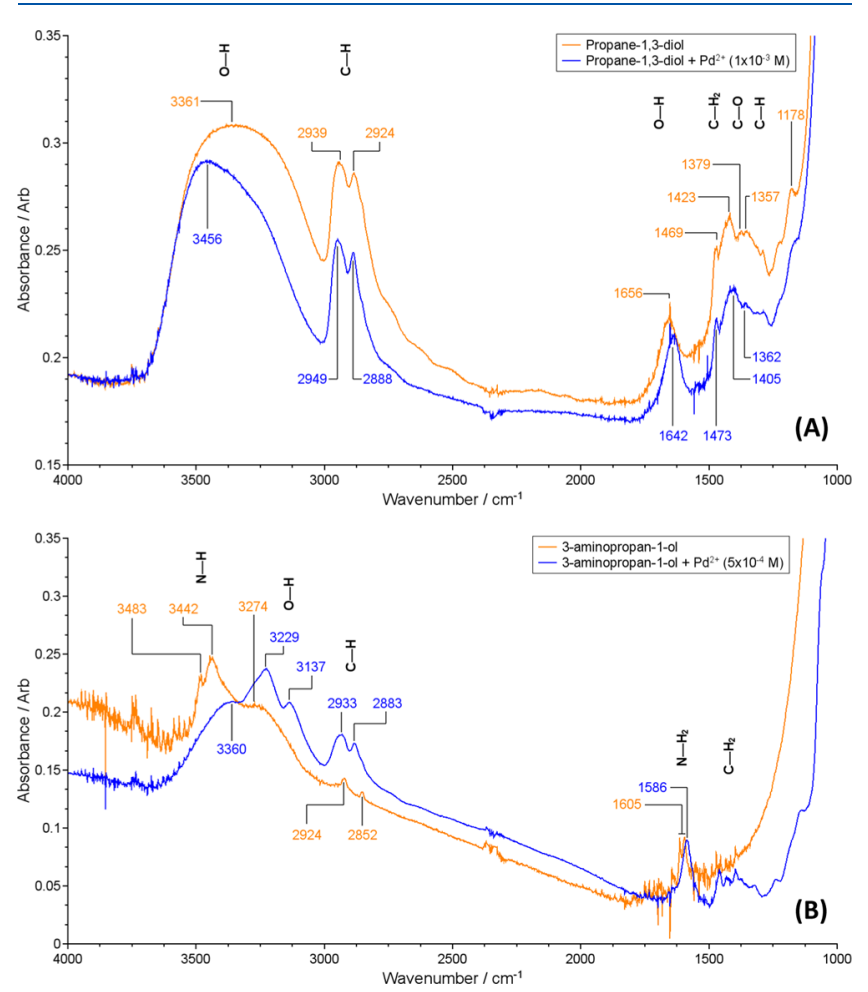

Figure 5. (A) FT-IR spectra of PD and Pd-PD (top). (B) FT-IR spectra of AP and Pd-AP (bottom).

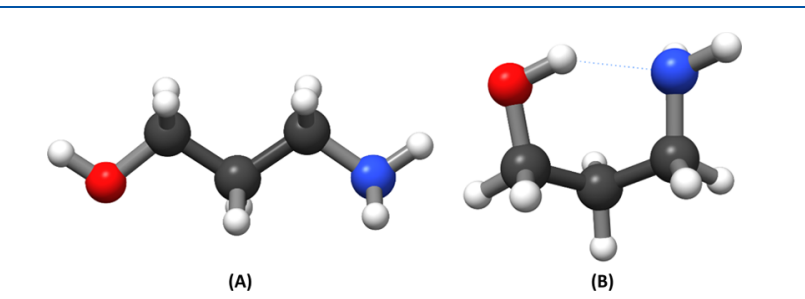

Figure 6. Optimization of two different conformations of the AP adsorbate in the gas phase: (A) all trans, (B) conformation with internal H-bond.

these species were obtained also using solid $\mathrm{PdCl}_{2}$ as the precursor by Freund et al., who collected UV-vis spectra of solutions depending on the $\mathrm{pH}$ of the media. ${ }^{70}$ At a $\mathrm{pH}$ of 1.3 , $\mathrm{d}-\mathrm{d}$ and CT transitions at $280 \mathrm{~nm} / 475 \mathrm{~nm}$ for $\mathrm{PdCl}_{4}{ }^{2-}$ and $320 \mathrm{~nm} / 430 \mathrm{~nm}$ for $\left[\mathrm{PdCl}_{3}\left(\mathrm{H}_{2} \mathrm{O}\right)\right]^{-}$, respectively, were observed. At a $\mathrm{pH}$ of 10, a spectrum showing increased background absorption was observed along with an increase at short wavelengths with a feature centered at $270 \mathrm{~nm}$. In addition, Grogan and Nakamoto reported the formation of dimeric species. $\mathrm{Pd}_{2} \mathrm{Cl}_{4}(\text { EthO })_{2}{ }^{2-}$ which can be described as a $\mathrm{Pd}$ analogue to the $\mathrm{Pt}$ salt Zeise's dimer. ${ }^{71}$

To identify the contribution of each of these species to the experimental spectra TD-DFT simulations were carried out to model UV-vis absorption spectra of $\mathrm{PdCl}_{4}{ }^{2-},\left[\mathrm{PdCl}_{3}\left(\mathrm{H}_{2} \mathrm{O}\right)\right]^{-}$, 
Table 3. Vibrational Frequencies and Assignments of the FT-IR Bands

\begin{tabular}{|c|c|}
\hline vibrational frequency $\left(\mathrm{cm}^{-1}\right)$ & assignment (vibrational mode) \\
\hline \multicolumn{2}{|c|}{ Bands Observed for PD } \\
\hline 3361 & $-\mathrm{OH}$ stretching \\
\hline 2939 and 2924 & $-\mathrm{CH}$ symm and asymm stretchings \\
\hline 1656 & $-\mathrm{OH}$ bending \\
\hline 1469 & $-\mathrm{CH}_{2}$ bending \\
\hline 1423 & $\mathrm{C}-\mathrm{O}$ stretching \\
\hline 1379 & $\mathrm{C}-\mathrm{H}$ bending \\
\hline \multicolumn{2}{|c|}{ Bands Observed for Pd-PD } \\
\hline 3456 & $-\mathrm{OH}$ stretching \\
\hline 2949 and 2888 & $-\mathrm{CH}$ symm and asymm stretchings \\
\hline 1642 & $-\mathrm{OH}$ bending \\
\hline 1473 & $-\mathrm{CH}_{2}$ bending \\
\hline 1405 & $\mathrm{C}-\mathrm{O}$ stretching \\
\hline 1362 & $\mathrm{C}-\mathrm{H}$ bending \\
\hline \multicolumn{2}{|c|}{ Bands Observed for AP } \\
\hline 3483 and 3442 & -NH symm and asymm stretching \\
\hline 3274 & $-\mathrm{OH}$ stretching \\
\hline 2924 and 2852 & $-\mathrm{CH}$ symm and asymm stretchings \\
\hline 1605 & -OH bending \\
\hline \multicolumn{2}{|c|}{ Bands Observed for Pd-AP } \\
\hline 3360 & $-\mathrm{OH}$ stretching \\
\hline 3229 and 3137 & $-\mathrm{NH}$ symm and asymm stretching \\
\hline 2933 and 2883 & $-\mathrm{CH}$ symm and asymm stretching \\
\hline 1586 & $-\mathrm{OH}$ bending \\
\hline
\end{tabular}

Table 4. Adsorption Energies of the Different Configurations of 3-Aminopropan-1-ol on $\operatorname{Pd}(100)$ and $\operatorname{Pd}(111)$ Surfaces

$\begin{array}{lcc}\text { configuration } & \begin{array}{c}\text { energy of } \\ \text { adsorption } / \mathrm{kJ} \mathrm{mol}^{-1}\end{array} & \begin{array}{c}\mathrm{N}-\mathrm{Pd} \text { or } \mathrm{O}-\mathrm{Pd} \\ \text { distance } / \AA\end{array} \\ \mathrm{Pd}(111) \text { surface } & -145 & 2.15 \\ \text { nitrogen binding } & -95 & 2.34 \\ \text { oxygen binding } & & \\ \mathrm{Pd}(100) \text { surface } \\ \text { nitrogen binding } \\ (\mathrm{O} \text { up })\end{array}$
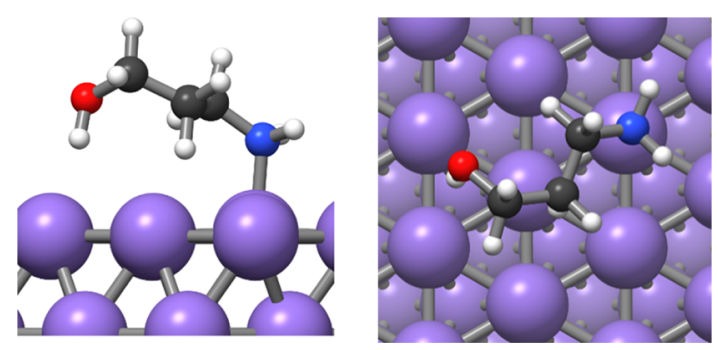

Figure 7. Adsorption of the AP adsorbate on the $\mathrm{Pd}(111)$ surface with the nitrogen binding to the surface.

and $\mathrm{Pd}_{2} \mathrm{Cl}_{6}^{2-}$ species. TD-DFT-computed UV-vis spectra of $\mathrm{PdCl}_{4}{ }^{2-}$ and $\mathrm{Pd}_{2} \mathrm{Cl}_{6}{ }^{2-}$ (green and blue dotted curves in Figure 1 , respectively) are in good agreement with the observed experimental spectrum (the black curve in Figure 1). The computed data for the chlorine bridged dimer indicate that the characteristic $420 \mathrm{~nm}$ band in the experimental spectra is due to $\mathrm{Cl} \mathrm{p}-\mathrm{Pd} \mathrm{s}$ transition. However, the breadth of this band is
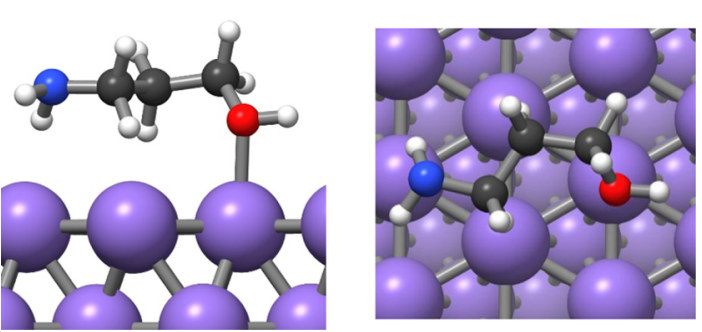

Figure 8. Adsorption of the $\mathrm{AP}$ adsorbate on the $\mathrm{Pd}(111)$ with the oxygen binding to the surface.

likely due to the contributions of $470 \mathrm{~nm}$ transition, indicating a predominantly $\mathrm{Pd} d$ to $\mathrm{Pd} p$ excitation involving both palladium ions of the dimer, and a $388 \mathrm{~nm}$ transition observed in the computed spectrum of $\mathrm{PdCl}_{4}{ }^{2-}$, attributable to a predominantly $\mathrm{p}-\mathrm{p}$ excitation from chlorine to palladium. Therefore, the experimental band centered at $418 \mathrm{~nm}$ could include all the contributions predicted by the model systems.

The inherently large uncertainty in the relative intensities of bands obtained using the TD-DFT methodology means that the position of the peaks is used to analyze the spectra. ${ }^{63}$ The broad band present at $425 \mathrm{~nm}$ is probably composed of a combination of peaks caused by contributions of the three computationally modeled structures. Furthermore, the shoulder observed in the experimental spectrum at $310 \mathrm{~nm}$ is consistent with the computed spectrum of the dimer shown in Figure 1B. The agreement of these computed excitations with experimental spectra suggests that the sol is composed of an equilibrium mixture of $\mathrm{Pd}_{2} \mathrm{Cl}_{6}{ }^{2-}, \mathrm{PdCl}_{4}{ }^{2-}$, and $\left[\mathrm{PdCl}_{3}\left(\mathrm{H}_{2} \mathrm{O}\right)\right]^{-}$. The existence of these species is also supported by the calculation of the energies of reaction for the formation of $\mathrm{Pd}_{2} \mathrm{Cl}_{6}{ }^{2-}$ and $\left[\mathrm{PdCl}_{3}\left(\mathrm{H}_{2} \mathrm{O}\right)\right]^{-}$from $\mathrm{PdCl}_{4}{ }^{2-}$, shown in Table 1 . These values indicate that the formation of the dimer and the water-containing complex are both exothermic processes with the dimer being the more energetically favorable.

The addition of the capping agent to the $\mathrm{Pd}^{2+}$ solution in PD led to no substantial changes in the observed spectrum (cyan dotted line vs blue line in Figure 2). Conversely, upon reduction with $\mathrm{NaBH}_{4}$ (red line), the band at $418 \mathrm{~nm}$ was not evident while an increased background absorption and an increase at short wavelengths with a maximum absorption at $285 \mathrm{~nm}$ were observed.

The observed increment in the background intensity can be attributed to the scattering induced by the formation of colloidal palladium particles and could be responsible for the masking/disappearance of the band at $418 \mathrm{~nm}$. The blue shift of the CT band could be correlated to the increase of $\mathrm{pH}$ because of the $\mathrm{NaBH}_{4}$ addition. However, the exact assignment of the observed band at $285 \mathrm{~nm}$ is still undetermined. According to Klasovsky et al., this peak relates to plasmon excitation in the colloidal particles. ${ }^{72}$ However, Boily argued that it is also compatible with a CT transition of Pd chlorohydroxo complexes, $\mathrm{PdCl}_{x}(\mathrm{OH})_{y}{ }^{n-}$, which are stable solution species under our experimental conditions according to the hydrolysis equilibrium. ${ }^{73}$

The effect of adding the AP capping agent to the sol $\mathrm{Pd}^{2+}$ with subsequent metal reduction is shown in Figure 3. As expected, the initial UV-vis spectrum of $\mathrm{Pd}(\mathrm{II})$ (blue line) is consistent with that of Figure 1, further pointing out the reproducibility of the experimental procedure. Upon addition of AP (green line), the broad band centered at $418 \mathrm{~nm}$ is 

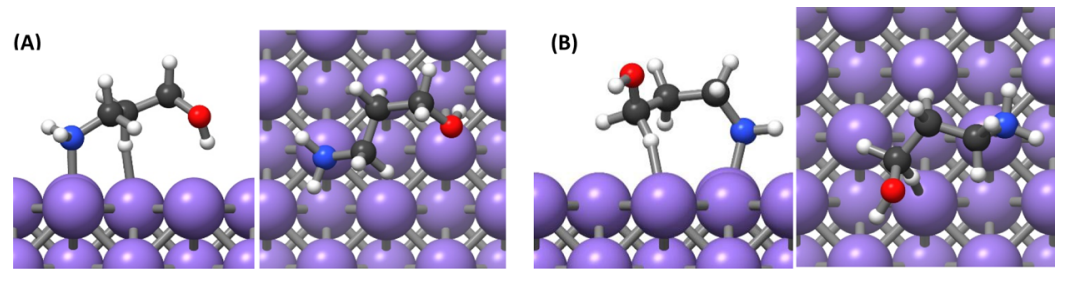

Figure 9. Adsorption of the AP adsorbate on $\mathrm{Pd}(100)$ with the nitrogen binding to the surface and (A) oxygen pointing downward and (B) oxygen pointing upward.
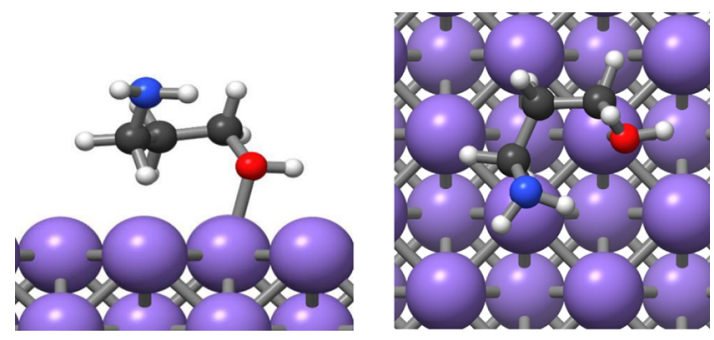

Figure 10. Adsorption of the AP adsorbate on $\operatorname{Pd}(100)$ with the oxygen binding to the surface.

depleted, and the decrease in intensity of the shoulder at 307 $\mathrm{nm}$ is accompanied by a broadening and a shift of the peak to $317 \mathrm{~nm}$. These significant changes are a consequence of the chlorine ligand substitution by the AP capping agent.

These results are consistent with the computational analysis; the TD-DFT spectrum of the most favorable product, $\left[\mathrm{PdCl}_{3} \mathrm{AP}\right]^{-}$, (Figure 4, dashed blue line) was also found to be consistent with the experimental results. The energies of reaction for the formation of aminopropanol ligand complexes from $\mathrm{PdCl}_{4}$ are shown in Table 2 .

The peak observed at $334 \mathrm{~nm}$ in the computational spectrum shows an excitation from a hybrid $\mathrm{Pd} \mathrm{d}-\mathrm{Cl} \mathrm{p}$ orbital to a molecular orbital composed from the palladium sp and a hybridization of orbitals in the aminopropanol ligand.

This agreement with the experimental spectrum strongly suggests that the aminopropanol is directly attached to a $\mathrm{Pd}^{2+}$ species in a structure consistent with the computational predictions. A similar suggestion was reported by Groppo et al. $^{32}$ who compared the diffuse reflectance UV-vis spectra of bulk $\mathrm{Pd}(\mathrm{OAc})_{2}$ diluted in $\mathrm{SiO}_{2}$ and in pyridine. The bulk $\mathrm{Pd}(\mathrm{OAc})_{2}$ in silica exhibited a band maximum at $400 \mathrm{~nm}$, whilst the one diluted in pyridine revealed a peak centered around $330 \mathrm{~nm}$. As a possible explanation, the authors suggested that one or two acetate ligands were substituted using pyridine units.

This interaction between the $\mathrm{NH}$ group and the $\mathrm{Pd}^{2+}$ ions involves a strong interaction between the electron-rich amino group and the metal ion, which could induce a change in the actual oxidation state of the metal by partial reduction. For this reason, centroid analysis of the Pipek-Mezey localised orbitals was utilized to examine the oxidation state of $\mathrm{Pd}$ and the character of the $\mathrm{AP}-$ metal bond, Figure 4B. The localized twocentered bonding orbitals indicated that the $\mathrm{Pd}-\mathrm{AP}$ bond was largely dative in character with the electrons in the bonding orbital being biased toward the more electronegative nitrogen. Analysis of the single atom orbitals showed the electronic configuration of the $\mathrm{Pd}$ atom to be consistent with $\mathrm{Pd}(\mathrm{II})$, $4 s^{2} 4 p^{6} 4 d^{8}$ because of the presence of eight centroids centered upon the $\mathrm{Pd}$ atom and the bonding orbital centroids being biased toward the ligands. Coordination of the ligand does not therefore involve a redox process.

Upon reduction with $\mathrm{NaBH}_{4}$, the UV-vis spectrum (Figure 3 , red line) assumed a very broad profile, where it is difficult to uniquely identify defined features or any eventual shifts. A significant increase in the background absorbance was indeed observed, which, as in the case of PD, was attributed to WillisTyndall scattering which is characteristic for the formation of particles.

In order to obtain more information on the coordination of $\mathrm{PD}$ and $\mathrm{AP}$ to $\mathrm{Pd}^{2+}$ ions, FT-IR spectra of the $\mathrm{Pd}(\mathrm{II})$ complexes were recorded and compared to the FT-IR spectra of the pure ligand molecules, as shown in Figure 5. In the case of propane-1,3-diol, Figure 5A, the interaction with $\mathrm{Pd}^{2+}$ ions seems to provoke negligible perturbations in the molecular structure of the ligand. Indeed, in addition to an overall decrease in intensity upon $\mathrm{Pd}^{2+}$ addition, only an erosion of the broad peak at $3361 \mathrm{~cm}^{-1}$ because of the stretching of $-\mathrm{OH}$ groups, together with a shift of the peak related to the $-\mathrm{OH}$ bending mode from 1656 to $1647 \mathrm{~cm}^{-1}$ are observed, which indicate that the presence of the $\mathrm{Pd}^{2+}$ ions perturbed these groups. This spectroscopic feature points out that the interaction between the metal ions and the propane-1,3-diol ligand occurs through the $-\mathrm{OH}$ groups.

Conversely, more significant changes were observed in the FT-IR spectrum of AP after interaction with $\mathrm{Pd}^{2+}$ ions (Figure $5 B$ ). The peaks observed at 3483 and $3442 \mathrm{~cm}^{-1}$, related to the symmetric and antisymmetric stretching modes of the $-\mathrm{NH}$ group, are decreased and new bands at 3229 and $3137 \mathrm{~cm}^{-1}$ are produced immediately upon the addition of $\mathrm{Pd}^{2+}$. Moreover, the $-\mathrm{N}-\mathrm{H}$ bending mode observed at $1605 \mathrm{~cm}^{-1}$ is shifted to $1586 \mathrm{~cm}^{-1}$. To rationalize these differences, in particular, to understand if the peaks at 3229 and $3137 \mathrm{~cm}^{-1}$ are the result of a marked shift of the symmetric and antisymmetric stretching modes of the $-\mathrm{NH}$ group or of a strong perturbation of the $-\mathrm{OH}$ group, frequency calculations were performed in order to simulate FT-IR spectra for the most stable conformations of the Pd(II)-AP complex.

Different configurations of the adsorbate were first optimized in the gas phase in order to determine the most stable configuration. Upon optimization with a plane-wave basis set and the PBE functional, a straight chain configuration and an internally hydrogen bonded conformation (with the hydroxyl oxygen to the amino nitrogen) were found to be the most favorable, with the latter being the most stable. The $\mathrm{H}$ bonded conformation was found to have an electronic energy $\approx 0.8 \mathrm{eV}$ lower than that of the other structure, which was also consistent with results obtained using an atom-centered basis set. The two configurations are shown in Figure 6.

These results confirmed the former hypothesis coming from the FT-IR discussion, indicating that the interaction between the metal ions and the AP ligand occurs through the $-\mathrm{NH}$ 

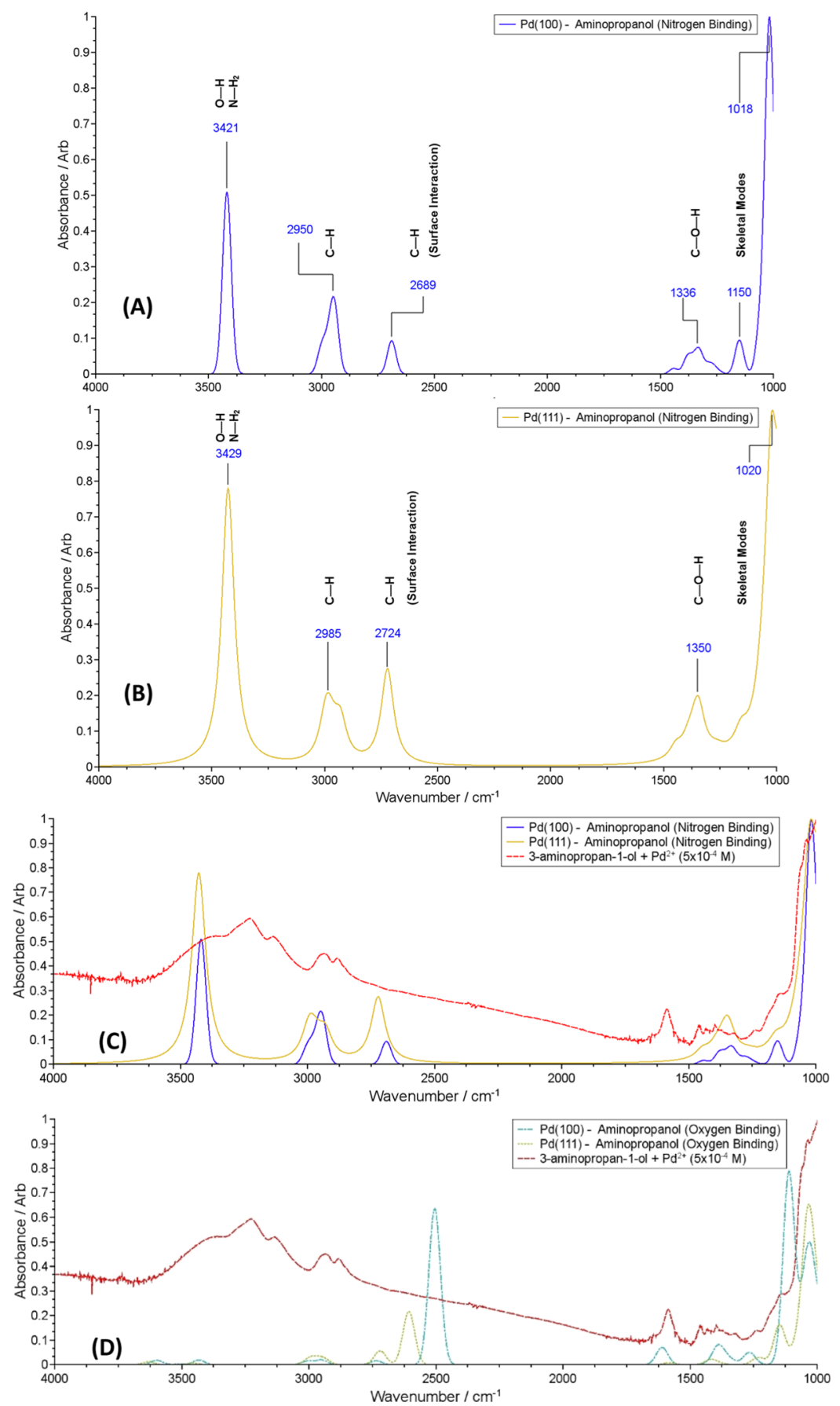

Figure 11. IR spectra for the most stable conformations: (A) nitrogen binding of the aminopropanol on the Pd(100) surface (B) nitrogen binding of the aminopropanol on the $\mathrm{Pd}(111)$ surface (C) plots A and B overlaid with the experimentally obtained IR spectrum, (D) oxygen binding on the $\operatorname{Pd}(111)$ and $\operatorname{Pd}(100)$ surfaces overlaid with the experimentally obtained IR spectrum.

group. The complete assignments of the FT-IR bands are summarized in Table 3.

For this reason, the interaction of the AP molecule with metallic Pd surfaces was also investigated. The most stable configuration of AP was then adsorbed on the two low index surfaces of palladium metal: $\operatorname{Pd}(111)$ and $\operatorname{Pd}(100)$. Structures with $\mathrm{AP}$ binding to the surface through the oxygen atom or the nitrogen atom were investigated; it was found that those in which both the oxygen and the nitrogen atom bind to the surface at the same time were unstable because of internal strain within the AP. In the case with AP adsorbed through the amine $\mathrm{N}$ atom, hydroxyl hydrogen is also attracted toward the surface. Table 4 and Figures 7-10 summarize the results obtained.

The conformation with the nitrogen interacting with $\mathrm{Pd}$ was found to be more stable on both $\operatorname{Pd}(111)$ and $\operatorname{Pd}(100)$ surfaces as was also seen for the molecular precursor. Because the $\operatorname{Pd}(111)$ surface is more stable than the $\operatorname{Pd}(100)$ surface, the bonding of the adsorbate to the $\operatorname{Pd}(100)$ surface is stronger. As a result, the ligand is preferentially adsorbed on $\operatorname{Pd}(100)$ facets, making the surface less accessible. The reduced accessibility of $\operatorname{Pd}(100)$ facets favors the NP growth on the $\operatorname{Pd}(111)$ facet, resulting in a greater surface area of $\operatorname{Pd}(100)$ facets. This observation confirms the important role of the 
capping agent in controlling the growth mechanism and directing the final particle shape. In addition, the selective blocking of the $\mathrm{Pd}(100)$ surface can have an important impact on the catalytic performances of Pd NPs.

Frequency calculations on the most stable configurations were performed and IR spectra were calculated. The resulting IR spectra for the different conformations are reported in Figure 11. The correlation between the experimental IR spectrum and the spectra obtained for the adsorbed configurations can be taken as a strong indication that the aminopropanol caps the NP surfaces by bonding through the amino moiety. This is further supported by the oxygen binding spectra which indicate that the $\mathrm{O}-\mathrm{H}$ vibrational modes are significantly less infrared active than the nitrogen binding $\mathrm{O}-$ $\mathrm{H}$ modes in both the experimental and computed nitrogen binding spectra. While the accuracy of the extended-surface model for many properties of small NPs is limited, the assignment of the spectrum to the $\mathrm{N}$-binding species should not be of concern. The spectra for the nitrogen binding of AP on the $\operatorname{Pd}(111)$ and $\operatorname{Pd}(100)$ surfaces are very similar. Given that the difference between the two surfaces is the number of surrounding atoms, it can be concluded that the coordination number of Pd has very little effect on the vibration energies. Therefore, if the NPs are small to the extent that the corner or edge sites are significant, the adsorption of AP on these sites is not likely to have a major effect on the resultant spectra.

\section{CONCLUSIONS}

The synergistic combination of experimental spectroscopies and DFT modeling has allowed us to determine the coordination of small ligand to Pd species during the MNP formation process. Interesting differences emerged between $\mathrm{O}$ and $\mathrm{N}$-containing ligands. In particular, it seems that AP reacts with the molecular precursors by displacing a chloride ion to form a $\mathrm{Pd}(\mathrm{II}) \mathrm{Cl}_{3} \mathrm{AP}$ complex. $\mathrm{AP}$ is able to direct the growth processes during the subsequent reduction by stabilizing the $\operatorname{Pd}(100)$ facets and thus exerting a directing influence upon the shape of the resultant metal NPs. Although these molecules are model systems and greater complexity is expected from the adsorption of macromolecules such as polymers, typically used as capping agents, these results help in understanding the phenomena occurring at the interface between the metal surface and the ligand layer. These data will also provide a stimulus to a deeper investigation on the role of the capping agent in metal NP synthesis and in their catalytic behavior.

\section{ASSOCIATED CONTENT}

\section{SI Supporting Information}

The Supporting Information is available free of charge at https://pubs.acs.org/doi/10.1021/acs.jpcc.9b09791.

Images of a commercial transmission cell for UV-vis; geometries in $X Y Z$ of optimized complexes employed in this work; and complementary theory-experiment IR spectrum of $\left[\mathrm{PdCl}_{3} \mathrm{AP}\right]^{2+}(\mathrm{PDF})$

\section{AUTHOR INFORMATION}

\section{Corresponding Authors}

Alberto Roldan - Cardiff Catalysis Institute, School of Chemistry, Cardiff University, CF10 3AT Cardiff, U.K.; Email: roldanmartinezA@cardiff.ac.uk
Alberto Villa - Dipartimento di Chimica, Università degli Studi di Milano, I-20133 Milano, Italy; @ orcid.org/0000-00018656-6256; Email: alberto.villa@unimi.it

\section{Authors}

Sebastiano Campisi - Dipartimento di Chimica, Università degli Studi di Milano, I-20133 Milano, Italy

Cameron Beevers - Cardiff Catalysis Institute, School of Chemistry, Cardiff University, CF10 3AT Cardiff, U.K.

Ali Nasrallah - Cardiff Catalysis Institute, School of Chemistry, Cardiff University, CF10 3AT Cardiff, U.K.

C. Richard A. Catlow - Cardiff Catalysis Institute, School of Chemistry, Cardiff University, CF10 3AT Cardiff, U.K.

Carine e. Chan-Thaw - Dipartimento di Chimica, Università degli Studi di Milano, I-20133 Milano, Italy

Maela Manzoli - Department of Drug Science and Technology and NIS-Centre for Nanostructured Interfaces and Surfaces, University of Turin, 10125 Turin, Italy; (i) orcid.org/00000002-4427-7939

Nikolaos Dimitratos - Dipartimento di Chimica Industriale e dei Materiali, Alma Mater Studiorum Università di Bologna, 40136 Bologna, Italy

David J. Willock - Cardiff Catalysis Institute, School of Chemistry, Cardiff University, CF10 3AT Cardiff, U.K.; (1) orcid.org/0000-0002-8893-1090

Complete contact information is available at: https://pubs.acs.org/10.1021/acs.jpcc.9b09791

\section{Notes}

The authors declare no competing financial interest.

\section{ACKNOWLEDGMENTS}

We acknowledge the support of the Supercomputing Wales project, which is partly funded by the European Regional Development Fund (ERDF) via Welsh Government. Via our membership of the UK's HEC Materials Chemistry Consortium, which is funded by EPSRC (EP/L000202), this work used the UK Materials and Molecular Modelling Hub for computational resources, which is partially funded by EPSRC (EP/P020194).

\section{REFERENCES}

(1) Tao, F. Metal Nanoparticles for Catalysis: Advances and Applications; RSC Catalysis Series; Royal Society of Chemistry, 2014.

(2) Capek, I. Noble Metal Nanoparticles: Preparation, Composite Nanostructures, Biodecoration and Collective Properties; Nanostructure Science and Technology; Springer Japan, 2017.

(3) Liu, L.; Corma, A. Metal Catalysts for Heterogeneous Catalysis: From Single Atoms to Nanoclusters and Nanoparticles. Chem. Rev. 2018, 118, 4981-5079.

(4) He, C.; Liu, D.; Lin, W. Nanomedicine Applications of Hybrid Nanomaterials Built from Metal-Ligand Coordination Bonds: Nanoscale Metal-Organic Frameworks and Nanoscale Coordination Polymers. Chem. Rev. 2015, 115, 11079-11108.

(5) Roldán, A.; Ricart, J. M.; Illas, F. Growth and Properties of Au Nanowires. Mol. Simul. 2009, 35, 1051-1056.

(6) Wu, Y.; Wang, D.; Li, Y. Nanocrystals from Solutions: Catalysts. Chem. Soc. Rev. 2014, 43, 2112-2124.

(7) Irzhak, V. I. The Mechanisms of the Formation of MetalContaining Nanoparticles. Rev. J. Chem. 2016, 6, 370-404.

(8) Qi, L.; Fresnais, J.; Berret, J.-F.; Castaing, J.-C.; Destremaut, F.; Salmon, J.-B.; Cousin, F.; Chapel, J.-P. Influence of the Formulation Process in Electrostatic Assembly of Nanoparticles and Macromolecules in Aqueous Solution: The Interaction Pathway. J. Phys. Chem. C 2010, 114, 16373-16381. 
(9) Chen, T.; Rodionov, V. O. Controllable Catalysis with Nanoparticles: Bimetallic Alloy Systems and Surface Adsorbates. ACS Catal. 2016, 6, 4025-4033.

(10) Cargnello, M. Colloidal Nanocrystals as Building Blocks for Well-Defined Heterogeneous Catalysts. Chem. Mater. 2019, 31, 576596.

(11) Liu, J.; Legros, S.; Ma, G.; Veinot, J. G. C.; von der Kammer, F.; Hofmann, T. Influence of Surface Functionalization and Particle Size on the Aggregation Kinetics of Engineered Nanoparticles. Chemosphere 2012, 87, 918-924.

(12) Oh, M.; Mirkin, C. A. Chemically Tailorable Colloidal Particles from Infinite Coordination Polymers. Nature 2005, 438, 651-654.

(13) Cortes-Huerto, R.; Goniakowski, J.; Noguera, C. Role of the Environment in the Stability of Anisotropic Gold Particles. Phys. Chem. Chem. Phys. 2015, 17, 6305-6313.

(14) Hosseini, S.; Alsiraey, N.; Riley, A. J.; Zubkov, T.; Closson, T.; Tye, J.; Bodappa, N.; Li, Z. Variable Growth and Characterizations of Monolayer-Protected Gold Nanoparticles Based on Molar Ratio of Gold and Capping Ligands. Langmuir 2018, 34, 15517-15525.

(15) Rode, B. M.; Schwenk, C. F.; Hofer, T. S.; Randolf, B. R. Coordination and Ligand Exchange Dynamics of Solvated Metal Ions. Coord. Chem. Rev. 2005, 249, 2993-3006.

(16) Liu, P.; Qin, R.; Fu, G.; Zheng, N. Surface Coordination Chemistry of Metal Nanomaterials. J. Am. Chem. Soc. 2017, 139, 2122-2131.

(17) Ortiz, N.; Skrabalak, S. E. On the Dual Roles of Ligands in the Synthesis of Colloidal Metal Nanostructures. Langmuir 2014, 30, 6649-6659.

(18) Costa, N. J. S.; Rossi, L. M. Synthesis of Supported Metal Nanoparticle Catalysts Using Ligand Assisted Methods. Nanoscale 2012, 4, 5826-5834.

(19) Varghese, N.; Rao, C. N. R. Growth kinetics of platinum nanocrystals prepared by two different methods: Role of the surface. $J$. Colloid Interface Sci. 2012, 365, 117-121.

(20) Mozaffari, S.; Li, W.; Thompson, C.; Ivanov, S.; Seifert, S.; Lee, B.; Kovarik, L.; Karim, A. M. Ligand-Mediated Nucleation and Growth of Palladium Metal Nanoparticles. J. Visualized Exp. 2018, 31, No. e57667.

(21) Yancey, D. F.; Chill, S. T.; Zhang, L.; Frenkel, A. I.; Henkelman, G.; Crooks, R. M. A Theoretical and Experimental Examination of Systematic Ligand-Induced Disorder in $\mathrm{Au}$ Dendrimer-Encapsulated Nanoparticles. Chem. Sci. 2013, 4, 2912.

(22) Hostetler, M. J.; Wingate, J. E.; Zhong, C.-J.; Harris, J. E.; Vachet, R. W.; Clark, M. R.; Londono, J. D.; Green, S. J.; Stokes, J. J.; Wignall, G. D.; et al. Alkanethiolate Gold Cluster Molecules with Core Diameters from 1.5 to $5.2 \mathrm{~nm}$ : Core and Monolayer Properties as a Function of Core Size. Langmuir 1998, 14, 17-30.

(23) Karim, A. M.; Al Hasan, N.; Ivanov, S.; Siefert, S.; Kelly, R. T.; Hallfors, N. G.; Benavidez, A.; Kovarik, L.; Jenkins, A.; Winans, R. E.; et al. Synthesis of $1 \mathrm{Nm}$ Pd Nanoparticles in a Microfluidic Reactor: Insights from in Situ X-Ray Absorption Fine Structure Spectroscopy and Small-Angle X-Ray Scattering. J. Phys. Chem. C 2015, 119, 13257-13267.

(24) Biacchi, A. J.; Schaak, R. E. The Solvent Matters: Kinetic versus Thermodynamic Shape Control in the Polyol Synthesis of Rhodium Nanoparticles. ACS Nano 2011, 5, 8089-8099.

(25) Mozaffari, S.; Li, W.; Thompson, C.; Ivanov, S.; Seifert, S.; Lee, B.; Kovarik, L.; Karim, A. M. Colloidal Nanoparticle Size Control: Experimental and Kinetic Modeling Investigation of the Ligandmetal Binding Role in Controlling the Nucleation and Growth Kinetics. Nanoscale 2017, 9, 13772-13785.

(26) Rossi, L. M.; Fiorio, J. L.; Garcia, M. A. S.; Ferraz, C. P. The Role and Fate of Capping Ligands in Colloidally Prepared Metal Nanoparticle Catalysts. Dalton Trans. 2018, 47, 5889-5915.

(27) Campisi, S.; Schiavoni, M.; Chan-Thaw, C.; Villa, A. Untangling the Role of the Capping Agent in Nanocatalysis: Recent Advances and Perspectives. Catalysts 2016, 6, 185.

(28) Campisi, S.; Ferri, D.; Villa, A.; Wang, W.; Wang, D.; Kröcher, O.; Prati, L. Selectivity Control in Palladium-Catalyzed Alcohol
Oxidation through Selective Blocking of Active Sites. J. Phys. Chem. C 2016, 120, 14027-14033.

(29) Lazzarini, A.; Groppo, E.; Agostini, G.; Borfecchia, E.; Giannici, F.; Portale, G.; Longo, A.; Pellegrini, R.; Lamberti, C. Formation and growth of palladium nanoparticles inside porous poly(4-vinylpyridine) monitored by operando techniques: The role of different reducing agents. Catal. Today 2017, 283, 144-150.

(30) Abécassis, B.; Testard, F.; Spalla, O.; Barboux, P. Probing in Situ the Nucleation and Growth of Gold Nanoparticles by SmallAngle X-Ray Scattering. Nano Lett. 2007, 7, 1723-1727.

(31) Yin, X.; Shi, M.; Wu, J.; Pan, Y.-T.; Gray, D. L.; Bertke, J. A.; Yang, $\mathrm{H}$. Quantitative Analysis of Different Formation Modes of Platinum Nanocrystals Controlled by Ligand Chemistry. Nano Lett. 2017, 17, 6146-6150.

(32) Groppo, E.; Agostini, G.; Borfecchia, E.; Wei, L.; Giannici, F.; Portale, G.; Longo, A.; Lamberti, C. Formation and Growth of Pd Nanoparticles inside a Highly Cross-Linked Polystyrene Support: Role of the Reducing Agent. J. Phys. Chem. C 2014, 118, 8406-8415.

(33) Begum, R.; Farooqi, Z. H.; Naseem, K.; Ali, F.; Batool, M.; Xiao, J.; Irfan, A. Applications of UV/Vis Spectroscopy in Characterization and Catalytic Activity of Noble Metal Nanoparticles Fabricated in Responsive Polymer Microgels: A Review. Crit. Rev. Anal. Chem. 2018, 48, 503-516.

(34) Bittner, M. M.; Kraus, D.; Lindeman, S. V.; Popescu, C. V.; Fiedler, A. T. Synthetic, Spectroscopic, and DFT Studies of Iron Complexes with Iminobenzo(semi)quinone Ligands: Implications for o-Aminophenol Dioxygenases. Chem.-Eur. J. 2013, 19, 9686-9698.

(35) Singh, D. K.; Jagannathan, R.; Khandelwal, P.; Abraham, P. M.; Poddar, P. In Situ Synthesis and Surface Functionalization of Gold Nanoparticles with Curcumin and Their Antioxidant Properties: An Experimental and Density Functional Theory Investigation. Nanoscale 2013, 5, 1882.

(36) Ansar, S. M.; Haputhanthri, R.; Edmonds, B.; Liu, D.; Yu, L.; Sygula, A.; Zhang, D. Determination of the Binding Affinity, Packing, and Conformation of Thiolate and Thione Ligands on Gold Nanoparticles. J. Phys. Chem. C 2011, 115, 653-660.

(37) Chen, M.; Feng, Y.-G.; Wang, X.; Li, T.-C.; Zhang, J.-Y.; Qian, D.-J. Silver Nanoparticles Capped by Oleylamine: Formation, Growth, and Self-Organization. Langmuir 2007, 23, 5296-5304.

(38) Groppo, E.; Agostini, G.; Borfecchia, E.; Lazzarini, A.; Liu, W.; Lamberti, C.; Giannici, F.; Portale, G.; Longo, A. The Pyridyl Functional Groups Guide the Formation of Pd Nanoparticles Inside A Porous Poly(4-Vinyl-Pyridine). ChemCatChem 2015, 7, 2188-2195.

(39) Garcia, M. A.; de la Venta, J.; Crespo, P.; Llopis, J.; Penadés, S.; Fernández, A.; Hernando, A. Surface Plasmon Resonance of Capped Au Nanoparticles. Phys. Rev. B: Condens. Matter Mater. Phys. 2005, 72, No. 241403(R).

(40) Cure, J.; Coppel, Y.; Dammak, T.; Fazzini, P. F.; Mlayah, A.; Chaudret, B.; Fau, P. Monitoring the Coordination of Amine Ligands on Silver Nanoparticles Using NMR and SERS. Langmuir 2015, 31, 1362-1367.

(41) Polte, J.; Ahner, T. T.; Delissen, F.; Sokolov, S.; Emmerling, F.; Thünemann, A. F.; Kraehnert, R. Mechanism of Gold Nanoparticle Formation in the Classical Citrate Synthesis Method Derived from Coupled in Situ XANES and SAXS Evaluation. J. Am. Chem. Soc. 2010, 132, 1296-1301.

(42) Biswas, K.; Varghese, N.; Rao, C. N. R. Growth Kinetics of Gold Nanocrystals: A Combined Small-Angle X-Ray Scattering and Calorimetric Study. Small 2008, 4, 649-655.

(43) Liao, H.-G.; Niu, K.; Zheng, H. Observation of Growth of Metal Nanoparticles. Chem. Commun. 2013, 49, 11720.

(44) Šloufová, I.; Vlčková, B.; Procházka, M.; Svoboda, J.; Vohlídal, J. Comparison of SERRS and RRS Excitation Profiles of [Fe(Tpy) 2 ] $2+\left(\right.$ Tpy $=2,2^{\prime}: 6^{\prime}, 2^{\prime \prime}$-Terpyridine $)$ Supported by DFT Calculations: Effect of the Electrostatic Bonding to Chloride-Modified Ag Nanoparticles on Its Vibrational and Electronic Structure. J. Raman Spectrosc. 2014, 45, 338-348.

(45) Neese, F. The ORCA Program System. Wiley Interdiscip. Rev.: Comput. Mol. Sci. 2012, 2, 73-78. 
(46) Kresse, G.; Hafner, J. Ab Initio Molecular Dynamics for Liquid Metals. Phys. Rev. B: Condens. Matter Mater. Phys. 1993, 47, 558-561.

(47) Kresse, G.; Hafner, J. Ab initio molecular-dynamics simulation of the liquid-metal-amorphous-semiconductor transition in germanium. Phys. Rev. B: Condens. Matter Mater. Phys. 1994, 49, 1425114269.

(48) Kresse, G.; Furthmüller, J. Efficient Iterative Schemes for $A b$ Initio Total-Energy Calculations Using a Plane-Wave Basis Set. Phys. Rev. B: Condens. Matter Mater. Phys. 1996, 54, 11169-11186.

(49) Kresse, G.; Furthmüller, J. Efficiency of Ab-Initio Total Energy Calculations for Metals and Semiconductors Using a Plane-Wave Basis Set. Comput. Mater. Sci. 1996, 6, 15-50.

(50) Perdew, J. P.; Burke, K.; Ernzerhof, M. Generalized Gradient Approximation Made Simple. Phys. Rev. Lett. 1996, 77, 3865-3868.

(51) Perdew, J. P.; Burke, K.; Ernzerhof, M. Generalized Gradient Approximation Made Simple [Phys. Rev. Lett. 77, 3865 (1996)]. Phys. Rev. Lett. 1997, 78, 1396.

(52) Blöchl, P. E. Projector Augmented-Wave Method. Phys. Rev. B: Condens. Matter Mater. Phys. 1994, 50, 17953-17979.

(53) Kresse, G.; Joubert, D. From Ultrasoft Pseudopotentials to the Projector Augmented-Wave Method. Phys. Rev. B: Condens. Matter Mater. Phys. 1999, 59, 1758-1775.

(54) Waller, M. P.; Braun, H.; Hojdis, N.; Bühl, M. Geometries of Second-Row Transition-Metal Complexes from Density-Functional Theory. J. Chem. Theory Comput. 2007, 3, 2234-2242.

(55) Grimme, S.; Antony, J.; Ehrlich, S.; Krieg, H. A Consistent and Accurate $A b$ Initio Parametrization of Density Functional Dispersion Correction (DFT-D) for the 94 Elements H-Pu. J. Chem. Phys. 2010, 132, 154104.

(56) Grimme, S.; Ehrlich, S.; Goerigk, L. Effect of the Damping Function in Dispersion Corrected Density Functional Theory. J. Comput. Chem. 2011, 32, 1456-1465.

(57) Grimme, S. Semiempirical GGA-Type Density Functional Constructed with a Long-Range Dispersion Correction. J. Comput. Chem. 2006, 27, 1787-1799.

(58) Valeev, E. F. Libint: A Library for the Evaluation of Molecular Integrals of Many-Body Operators over Gaussian Functions; GitHub, 2018.

(59) Monkhorst, H. J.; Pack, J. D. Special Points for Brillouin-Zone Integrations. Phys. Rev. B: Solid State 1976, 13, 5188-5192.

(60) Andrae, D.; Häußermann, U.; Dolg, M.; Stoll, H.; Preuß, H. Energy-Adjusted ab Initio Pseudopotentials for the Second and Third Row Transition Elements. Theor. Chim. Acta 1990, 77, 123-141.

(61) Weigend, F.; Ahlrichs, R. Balanced Basis Sets of Split Valence, Triple Zeta Valence and Quadruple Zeta Valence Quality for H to Rn: Design and Assessment of Accuracy. Phys. Chem. Chem. Phys. 2005, 7, 3297.

(62) Weigend, F. Accurate Coulomb-Fitting Basis Sets for H to Rn. Phys. Chem. Chem. Phys. 2006, 8, 1057.

(63) Grimme, S. A Simplified Tamm-Dancoff Density Functional Approach for the Electronic Excitation Spectra of Very Large Molecules. J. Chem. Phys. 2013, 138, 244104.

(64) Lu, T.; Chen, F. Multiwfn: A Multifunctional Wavefunction Analyzer. J. Comput. Chem. 2012, 33, 580-592.

(65) Lu, T.; Chen, F. W. Calculation of Molecular Orbital Composition. Acta Chim. Sin. 2011, 69, 2393-2406.

(66) Vidossich, P.; Lledós, A. The Use of Localised Orbitals for the Bonding and Mechanistic Analysis of Organometallic Compounds. Dalton Trans. 2014, 43, 11145-11151.

(67) Pipek, J.; Mezey, P. G. A fast intrinsic localization procedure applicable for ab initio and semiempirical linear combination of atomic orbital wave functions. J. Chem. Phys. 1989, 90, 4916-4926.

(68) Sit, P. H.-L.; Zipoli, F.; Chen, J.; Car, R.; Cohen, M. H.; Selloni, A. Oxidation State Changes and Electron Flow in Enzymatic Catalysis and Electrocatalysis through Wannier-Function Analysis. Chem.-Eur. J. 2011, 17, 12136-12143.

(69) Elding, L. I. Palladium(II) halide complexes, II. Acid hydrolysis and halide anions of palladium(II) chloro and bromo aqua complexes. Inorg. Chim. Acta 1972, 6, 683-688.
(70) Wang, H.-F.; Kaden, W. E.; Dowler, R.; Sterrer, M.; Freund, H.$\mathrm{J}$. Model oxide-supported metal catalysts-comparison of ultrahigh vacuum and solution based preparation of $\mathrm{Pd}$ nanoparticles on a single-crystalline oxide substrate. Phys. Chem. Chem. Phys. 2012, 14, 11525-11533.

(71) Grogan, M. J.; Nakamoto, K. Infrared Spectra and Normal Coordinate Analysis of Metal-Olefin Complexes. II. Zeise's Dimer and Its Palladium(II) Analog. J. Am. Chem. Soc. 1968, 90, 918-922.

(72) Klasovsky, F.; Claus, P.; Wolf, D. Influence of Preparation Parameters on the Performance of Colloid-Derived Oxidic Palladium Catalysts for Selective Hydrogenation of $\mathrm{C}-\mathrm{C}$ Triple Bonds. Top. Catal. 2009, 52, 412-423.

(73) Boily, J.-F.; Seward, T. M.; Charnock, J. M. The hydrolysis and precipitation of $\mathrm{Pd}(\mathrm{II})$ in $0.6 \mathrm{~mol} \mathrm{~kg}{ }^{-1} \mathrm{NaCl}$ : A potentiometric, spectrophotometric, and EXAFS study. Geochim. Cosmochim. Acta 2007, 71, 4834-4845. 